\title{
The Hidden Face of Cultural Heritage: a science window for the dissemination of elementary knowledge of risk and vulnerability in cultural heritage
}

\author{
Pilar Ortiz ${ }^{1 *}$, Rocío Ortiz , José María Martín, Rosario Rodríguez-Griñolo², María Auxiliadora Vázquez³, \\ María Auxiliadora Gómez-Morón ${ }^{4}$, Marta Sameño ${ }^{4}$, Luisa Loza ${ }^{4}$, Carmen Guerra ${ }^{5}$ Juan Manuel Macías-Bernal ${ }^{6}$ \\ and Javier Becerra ${ }^{1}$
}

\begin{abstract}
The dissemination of research in cultural heritage preservation to the public is a task that needs new models and expressions, to capture the attention of the public and the assessment of results. With this purpose, a new educational experience in Parque de las Ciencias (Science Park of Granada, Spain) was developed. The science window titled Hidden Face of Cultural Heritage ( $\mathrm{ScW}-\mathrm{CH}$ ) was an exhibition to show the risks (hazards + vulnerability) associated to different artworks and materials of our cultural heritage $(\mathrm{CH})$. ScW- $\mathrm{CH}$ was led by the researchers themselves, in collaboration with museum specialists, in order to develop a new model that makes their research accessible to all demographics. An innovative methodology based into simulating a showcase, was designed to study hazards and vulnerability in $\mathrm{CH}$. Therefore, the montage contained materials, equipment, information sheets, and guides to accompany visitors as storytellers. The aim of the exhibition, was for the visitors to understand the risks posed to our monuments and artworks from a scientific point of view, and to raise awareness about the care that we should give to our $\mathrm{CH}$. The ScW-CH was held for 6 months and visited by 8226 visitors. During the exhibition, a survey about the opinion of visitors was carried out to study the impact of the designed new model and assess the results of the experience. The collected data was analysed by the Statistical Package for the Social Sciences (version 22.0). Visitors usually presented a medium-high initial interest about visiting this exhibition, and a medium-low level of knowledge of this subject. Thanks to $\mathrm{ScW}-\mathrm{CH}, 92 \%$ of visitors showed a very high learning level after the experience. The ratio of interest and learning in the ScW-CH in relationship with the level of study showed that secondary school pupils had the highest degree of interest and learning.
\end{abstract}

Keywords: Dissemination, Assessment, Science museum, Risk and cultural heritage, Heritage education

\section{Introduction}

Since ancient times the scientific method has been applied to the creation of works of art. For example, Pliny the Elder narrated the discovery of glass in his writings. This rapport between science and art has been intensified since the nineteenth century with the objective of

\footnotetext{
${ }^{*}$ Correspondence: mportcal@upo.es

${ }^{1}$ Dept. de Sistemas Físicos, Químicos y Naturales, Universidad Pablo de

Olavide, Carretera de Utrera km 1,41013 Seville, Spain

Full list of author information is available at the end of the article
}

developing new methods of diagnosis and conservation that allow us to know and conserve cultural heritage $(\mathrm{CH})$.

The need to communicate about science and technology to a growing interested public has resulted in the creation of scientific journals in different fields in which researchers explain their results [1]. However, dissemination is often more complicated and beyond researchers' reach even though it is a social imperative. In order to prepare the science window titled Hidden Face of 
Cultural Heritage $(\mathrm{ScW}-\mathrm{CH})$, it was taken into account that the dissemination of science and $\mathrm{CH}$ is a hard task and it is becoming more necessary given the lack of science vocations in recent years [2]. The need to explain investment in $\mathrm{R} \& \mathrm{D}+\mathrm{i}$ and $\mathrm{CH}$ conservation to the society during a global recession is very important, increasing science literacy in a variety of forms, from blogs to newspapers, from museums to public events, from films to radio shows. Besides, communication of science makes developing a scientific culture in society, improving scientific literacy and motivating talent surrounding scientific research, possible. Various authors present tools and programmes to improve the diffusion of scientific careers $[3,4]$ and arouse interest in children, teenagers and young people, or to disseminate the principles of cultural fields $[5,6]$. The actions of dissemination can generate a rise of about $6 \%$ in the number of young people wanting to study science or technology [7]. Roigé [8] evaluated that these methodologies could be applied from the point of view of the design of other exhibitions, highlighting the power of a good museography to get the immersion, leisure and fun of the visitants. In Spain and Portugal, countries with a cultural tradition centred in literature and arts, the promotion of scientific education in every field and its relationship with the arts is especially relevant. The social relevance of diffusion in all education levels is quoted by numerous authors focused on science dissemination [9]. Moreover, safeguarding and fully developing $\mathrm{CH}$ produces a great set of heterogeneous historical data, which are enriching a new virtual framework often based on open-source software $[10,11]$. The results of these methods for dissemination are rarely explained and assessed, because of this, our paper presents the methodology employed for the design of the exhibition and evaluation of the satisfaction results of end-users.

$\mathrm{ScW}-\mathrm{CH}$ was designed as an exhibition of artworks, their constructive materials and their vulnerability in the Science Park of Granada (Spain). This exhibition, part of a $R \& D+i$ project, was funded by Junta de Andalucía (Economy, Innovation, Science and Employment), the Science Park of Granada and different Andalusian universities. The main objective was to reveal to demographics the Andalusian research project HUM-6775 (http:// www.upo.es/tym/en_rivuph.html) for the study of risk, as a function of hazards and vulnerability in $\mathrm{CH}$. Other objectives were: to focus on our researchers and their activity in society, to raise awareness of the importance of $\mathrm{R} \& \mathrm{D}+\mathrm{i}$ in a modern, sustainable and democratic society in order to preserve their $\mathrm{CH}$, to promote scientific vocations in relationship with $\mathrm{CH}$ protection, to highlight the role of women on $\mathrm{CH}$ research, as well as to showcase collaborations between universities and companies to generate and share knowledge on $\mathrm{CH}$ conservation.
The exhibition had a large window, through which visitors could see a minilab to understand the artworks and their life. Once they decided to enter, they could carry out activities, meet our researchers, work with laboratory equipment and feel artwork materials, listen to the guide's explanations or play a game about weathering forms of $\mathrm{CH}$. In this manner, in the same space, our work gathers models of diffusion that could be helpful to children, teenagers and university students because the expressions were adapted according to the recommendations of Forbes [12]. Furthermore, there were modules to pique the scientific curiosity of professionals and researchers towards the science applied to $\mathrm{CH}$ and new information and communications technologies (ICT). This design tried to connect to the new museography, where museums have evolved from spaces exhibiting artwork collections to dynamic spaces where people go through eye-opening experiences. This leisure experiences were based on researching and learning with help from new technologies [13, 14], especially in the case of children and teenagers.

This model seeks to connect science with $\mathrm{CH}$, which involves the development of more creative exhibition methodologies that can encourage society to visit our $\mathrm{ScW}-\mathrm{CH}$ to understand the risk of $\mathrm{CH}$. With that aim, common discourses of current museums such as the hand-on exhibition approach, interactive technology exhibition and storytellers, were selected according to Ahmad et al. [15], Hashim et al. [16], Palombini [17] and Alanazi [18]. As the research conducted was in $\mathrm{CH}$, the typical sensitivities of art museums also had to be taken into account for the exhibition. Furthermore, the exhibition focused on the multidisciplinary nature of diagnosis, with a space called "the researchers' corner" where visitors could meet the researcher, and find out more about their careers: physicists, chemists, geologists, architects, biologists, archaeologists, historians, restorers, etc. working together as a team in order to preserve artworks. The role of women in this context was noted by the fact that most of these researchers were female, as well as the team leader.

This hands-on lab was awarded as the second prize of the Reach.Out! competition 2015 held by the European Materials Research Society as a public outreach activity whose main aim was to reveal, to the non-specialists, applications related to advanced materials, their impact on the creation of sustainable societies, their impact on the economy, the people behind the scenes and the complexity of the work performed (http://www. emrs-strasbourg.com/index.php?option $=$ com_conte nt\&task $=$ view\&id $=748 \&$ Itemid $=1641$ ). 


\section{Methodology and materials}

"The Hidden Face of Cultural Heritage" was built up as a science window that explains the research and collaborations in a real project RIVUHP (HUM-6775), aiming to develop a new model that makes its research accessible to all demographics. This exhibition at the Science Park of Granada (Spain) was held from July 2014 until January 2015. During this time period, the museum space explained the way to study the risks of our $\mathrm{CH}$ from the point of view of science and analytical techniques.

\section{Design of exhibition}

In the design of the exhibition space, it was taken into account that the study of risks as a function of hazards and vulnerability for $\mathrm{CH}$ requires an exhaustive understanding of four levels of knowledge:

1. Materials: stones, wood, metals, pigments, ceramics, varnishes, etc. and weathering forms.

2. Artworks as a complex mixture of materials with historical and artistic value.

3. The analytical techniques and methods available for diagnosis [optical microscopy, scanning electron microscope/energy-dispersive x-ray (SEM-EDX), infrared reflectography, ultrasound, laser-induced breakdown spectroscopy (LIBS), laser-induced fluorescence (LIF),...] and/or restoration (decontamination, laser cleaning, consolidating treatments including nanoparticles...).

4. Hazard assessment and vulnerability models to know the risks of our $\mathrm{CH}$.

The exhibition was based on an instructive design of learning and the evaluation of the dissemination results. This model consisted of five stages (Fig. 1) to get the audience to understand the four levels of diagnosis in cultural heritage: meetings to evaluate the space and the examples to be shown, writing of the guide files using expressions accessible to different levels, assembly of the exhibition with the training of guides, inauguration and exposition, and finally, evaluation of results.

The first phase of the model was the design of the exhibition space and its contents. The exposition was designed like a big showcase that captured the interest of the visitors of the Science Park and allowed them to see a minilab. Once the visitor decided to enter, they found an exhibition space that was understood as a unique space where the visitor could walk around the Researchers' Corner, where they could become a researcher and carried out their activities, watched videos or mini documentaries, surfed web links, used laboratory equipments and materials, listened to the guide's experimental explanation, or played a game of weathering forms, to understand the researchers' work.

The second phase of the model consisted of writing explanatory brochures. The guide files had a maximum length of one page and were made to cover the four levels of difficulty.

For 1 week the researchers and museum specialists assembled the exhibition, which had to be evaluated at a visual and scientific level before inauguration. During this third phase, the exhibition guides were trained by the researchers so that they could understand the research done on science for $\mathrm{CH}$ and act as storytellers during the guided visits.

\section{Public and statistical studies}

The participants were 8226 visitors of the museum, from children to the elderly, with different knowledge levels.

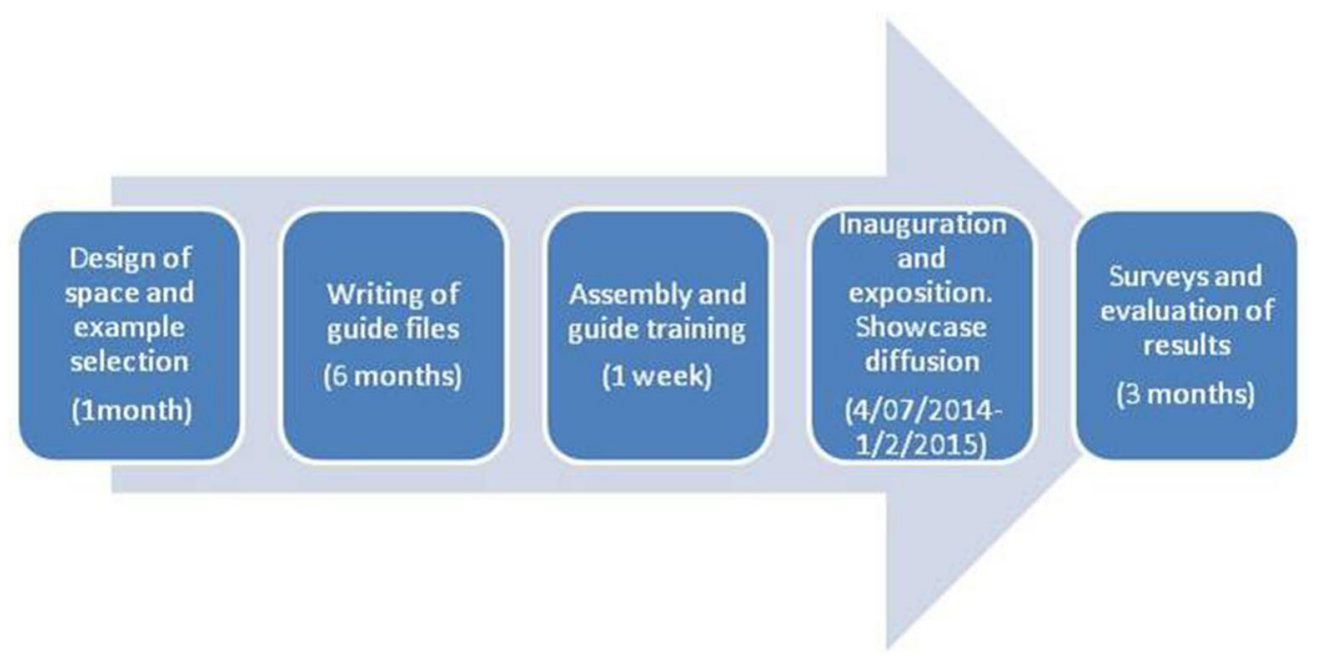

Fig. 1 Process of design, development and evaluation of the showcase 
Visitors learnt to evaluate the vulnerability of $\mathrm{CH}$ studying the original materials, their weathering forms, as well as hazards and risks associated to $\mathrm{CH}$.

The inauguration was held on 4th July 2014, and the model was exhibited for 6 months, in that time period the guides showed the model and carried out a survey about the opinion of visitors. 260 visitors or teams of visitors (families, friends, etc.) answered the survey, which means $3.1 \%$ of the visitors. The collected data was analysed by Statistical Package for the Social Sciences (SPSS) (version 22.0). Given the discrete nature of some variables studied on the survey, a non-parametric test, the medium equality test, was employed to compare the behaviour of different age and interest groups. The signification level set was $5 \%$. Data analysis and impact of the dissemination were study to assess the results of the experience.

\section{Results}

ScW-CH: application of a new exhibition methodology. Implantation and exhibition

The science Windows "The Hidden Face of Cultural Heritage" ScW-CH was developed as a place where visitors could enter a unique laboratory to explore different aspect to conform the research about $\mathrm{CH}$ from the constructive materials (pigments of a painting, cathedral stones, alloy cannons,...), the principal altering agents and their consequences on monuments (biological attacks on wood, wind action over stone,....) up to the processes to eliminate them, for example, how biological attacks on wood can be eliminated using inert gas by anoxia treatment.

To reach the most advanced level of knowledge in the models of hazards and vulnerability, the visitors must understand the ecosystem made up by the environment and $\mathrm{CH}$. Indeed, these influences define the risks of $\mathrm{CH}$. The scale of these risks ranges from cities and their problems (e.g. earthquakes that affect monuments) to humidity-temperature conditions and biological factors that can damage artworks.

As can be seen in the 3D blueprints (Figs. 2, 3), the minilab was designed among artworks, while a diffusion screen showed an image loop of the four levels of knowledge and photographs of the researchers working in the lab or in the monuments. In addition, this wall contains two big posters: the first was a collage to attract potential

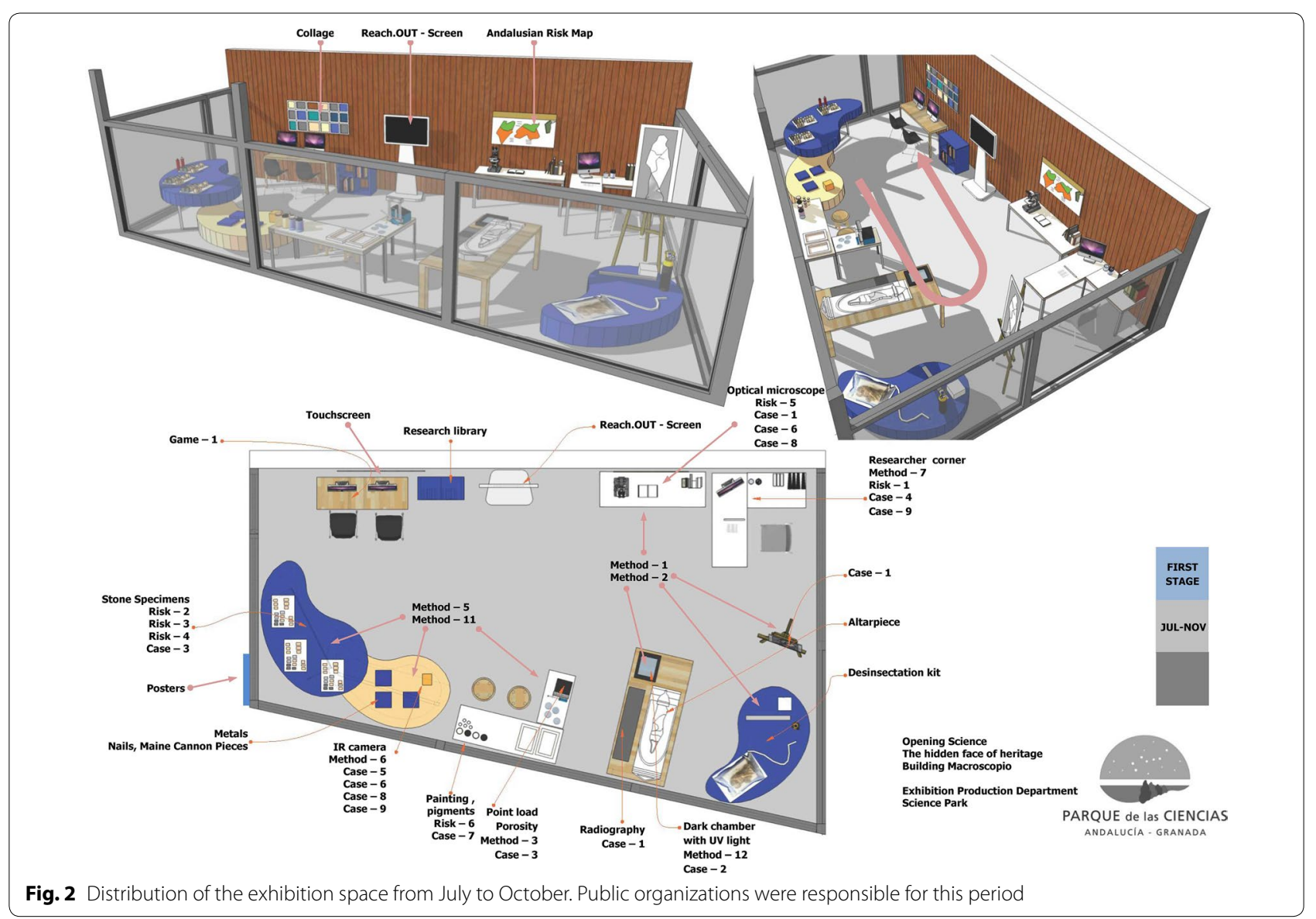




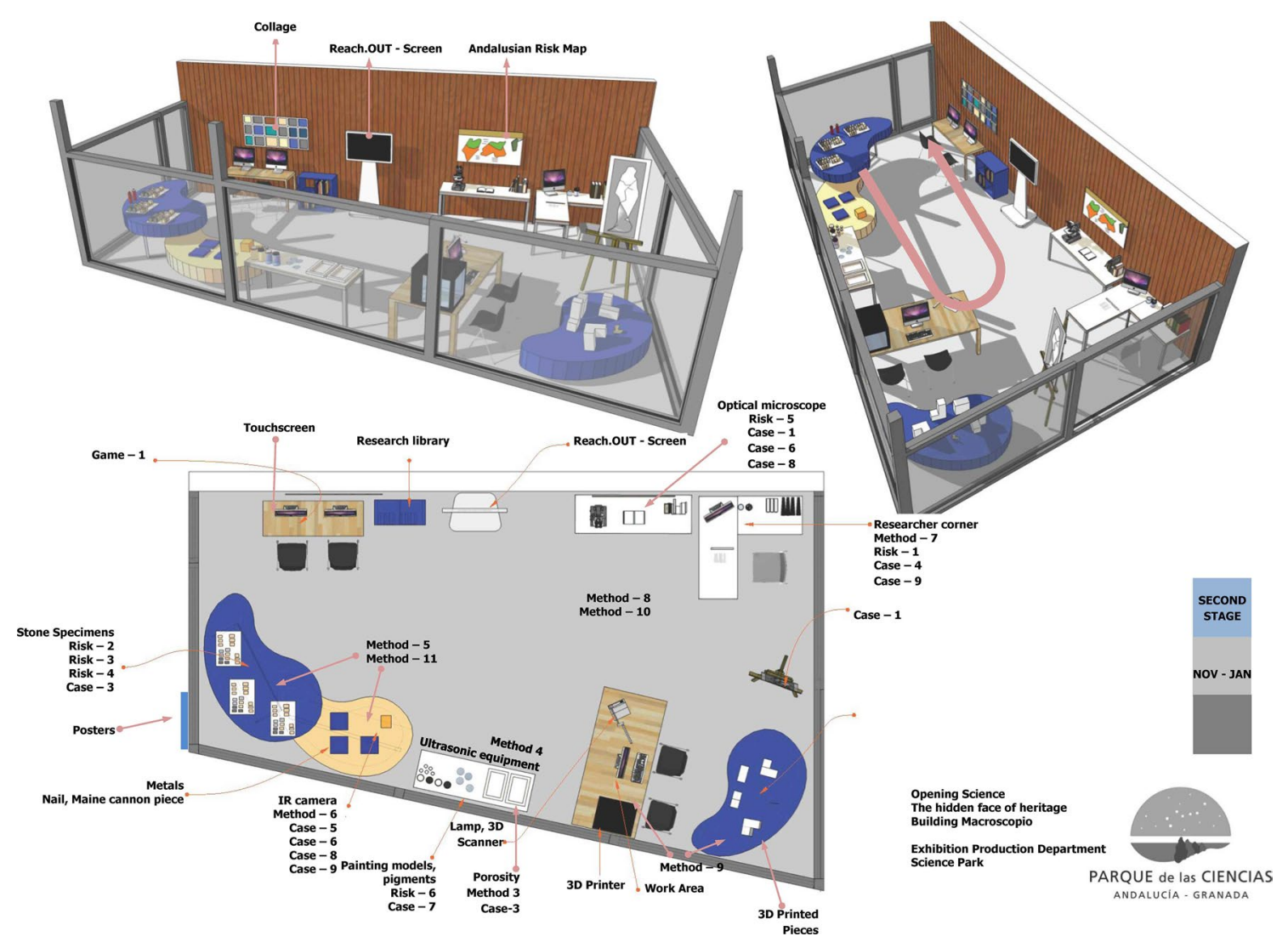

Fig. 3 Distribution of the exhibition space from October to January. Results and the opportunities of collaboration between private and public companies were shown in this period

visitors and the other contains the results of the research project (a cultural heritage risk map of Andalusia). The space was complemented with activities, exhibition elements, books, articles, congress posters, etc. The design of the exhibition space was modified according to the evolution of the files that had been written, as well as the opinion of everyone involved in the assembly. Finally, 27 guide brochures were made: 6 files about risks, 13 files about methods and 8 files about real cases. A pairing game for children was also made. In general, these files have been classified according to their exhibition method, as active, which implies that interaction is needed by the visitor: (a) manually, mainly related with equipment and laboratory management, or (b) using computers and their selection of programmes or multimedia content. Other files are passive, and the visitor must listen to the guide's explanation while observing $\mathrm{CH}$ materials, methods and results.

From the target audience's point of view there were zones for all types of public, from specific games for children to a book of posters of scientific sessions for researchers. Table 1 shows a summary of the content and the activities carried out during the exhibition.
In that regard, this model of work allows us to design a visual and attractive exhibition zone to catch the attention and interest of visitors. One of the most complicated aims of this exhibition was to make it accessible and interesting for all kind of visitors. It was achieved by the participation on its design of a multidisciplinary team that ranged from exhibitions designers to researchers. The exhibition was adapted to different groups of visitors (children, youth and adults) depending on their predicted interest and previous knowledge on the subject.

In order to show the personality and proximity of researchers, introduction videos of all participants were recorded. As it has already been mentioned, images of working researchers were shown on the screens and the researcher's profile could be looked up in the Researchers' Corner. The research team is mainly composed of women, so the image for the poster announcing the showcase was centred in a mosaic in which women are protagonists. This subtle detail also seeks to empower the role of women in this sector.

Besides, one of the key points was to show the multidisciplinary nature and the need for collaborations between organizations. In this sense, the researchers' corner 
revealed the diversity of professions required: physicists, chemists, geologists, architects, biologists, restorers, archaeologists, historians, etc. In order to explain the work carried out in public research centres and private companies, the exhibition was divided into two different time periods, where the space was modified according to Figs. 2 and 3. Both figures explain the equipment, zones and guide files of the two exhibition periods. The same file could be used by monitors for different exhibition zones, and in this way continue through the area that captivated the visitor's attention the most.

In summary, thanks to the application of this methodology to design the exhibition and the proposed resources, visitors could learn to evaluate the vulnerability of $\mathrm{CH}$. In this way, the aim was that the public studied with a guide how our ancestors painted, made their tools or built their buildings, and moreover visitors were encouraged to analyse the risks posed to our monuments and the artworks they contain, to understand the care we should give to our $\mathrm{CH}$.

\section{Data analysis and impact of the dissemination}

8226 visitors entered our showcase from July 2014 to January 2015, an average of 1175 visitors per month; that is $2.7 \%$ of visitors to the Science Park in Granada. A survey was carried out in order to evaluate the opinion of those people whom the project had reached, their aims and how they were met, the social and economic aspects, the stakeholders' gain and feedback.

The survey data shows a very close proportion of men/ women (53/47), with the number of men visiting the exhibition being slightly higher than that of women.

Around $45 \%$ of the visitors were younger than 19 years of age, one of the target audiences for the dissemination of science and scientific careers. The rest of the visitors, 25-30\%, were aged between 20 and 29 years, possibly university students or postgraduates. A similar percentage of visitors was aged between 30 and 60 years of age. People over the age of 60 represented only a small percentage of around 2\% (Table 2) of those who answered the survey. For this reason, they have been removed from the statistical correlation analysis.

Table 3 shows the study level of the people surveyed. Around $45 \%$ of the visitors had university studies, followed by those with secondary studies which make up around $32 \%$ of the total. Visitors with university studies were homogeneously spread between all those groups who are old enough, resulting in around one out of every two visitors for those aged between 20 and 60 years old. Taking into account that the percentage of university students in Spain is $41.1 \%$, this means that the surveys reflect the type of Spanish population, even if there is a greater trend to visit the exhibition among people with higher studies.

Approximately 6 out of 10 visitors were from Granada or its province (Tables 2 and 4) while 25\% were from the rest of Andalusia and the remaining 15\% came from other Spanish regions. The foreigners visiting the showcase were scarce (1\%) according to the survey, and if they did visit it they did not fill out the survey. This piece of information may be related to the fact that the survey is only in Spanish.

This regional distribution corresponds with the $42 \%$ of visitors who completed the survey and said that they visit the park on a regular basis (Table 2), due to its geographical proximity (Table 4).

The visit is supposedly ludic for $80 \%$ of the people surveyed, who visited with friends (Table 2). However, contrary to expectations the weekend only makes up about $34 \%$ of visits (Table 2).

The visitors surveyed showed a medium-high initial interest (values 3-5) in coming to this exhibition space, with the interest being very high in $32 \%$ of the people surveyed (Table 2). The interest in this exhibit varies significantly between different age groups ( $\mathrm{p}$-value $<0.5$ in the medium equality test), with those younger than 19 presenting a greater interest (Table 5, Fig. 4). In contrast, the visitors surveyed present medium-low knowledge of the exhibition, with up to $18 \%$ of visitors stating that they did not know anything about the field of risk, hazard and vulnerability in $\mathrm{CH}$. After the experience, $92 \%$ valued their level of learning between 8 and 10 on a scale of 10 . The average level of learning by ages is shown in Table 5 , where, although differences are only a half point away from the others, under-19s acknowledge learning the most.

The relationship between interest and learning in the showcase and the level of studies shows that primary students present the highest degree of interest and learning (4.02, average interest-9.5 average learning. Table 5).

Regarding the analysis of the exhibition space and the resources employed, 9 out of 10 visitors surveyed considered the exhibition to be well signalled (Table 2) and 62\% evaluated the assembly as excellent.

The communication skill was evaluated as excellent by around $73 \%$ of the people surveyed (Table 2) and the quality of the texts and audio-visual resources were assessed as good-excellent by around $80 \%$ of those surveyed (Table 2 ). The workshop was valued as excellent by $66 \%$ of those surveyed (Table 2 ).

In addition to the direct impact generated by visitors, the local and national press talked about this science showcase, as can be seen on Table 6. However, people who visited the showcase admitted that they became 


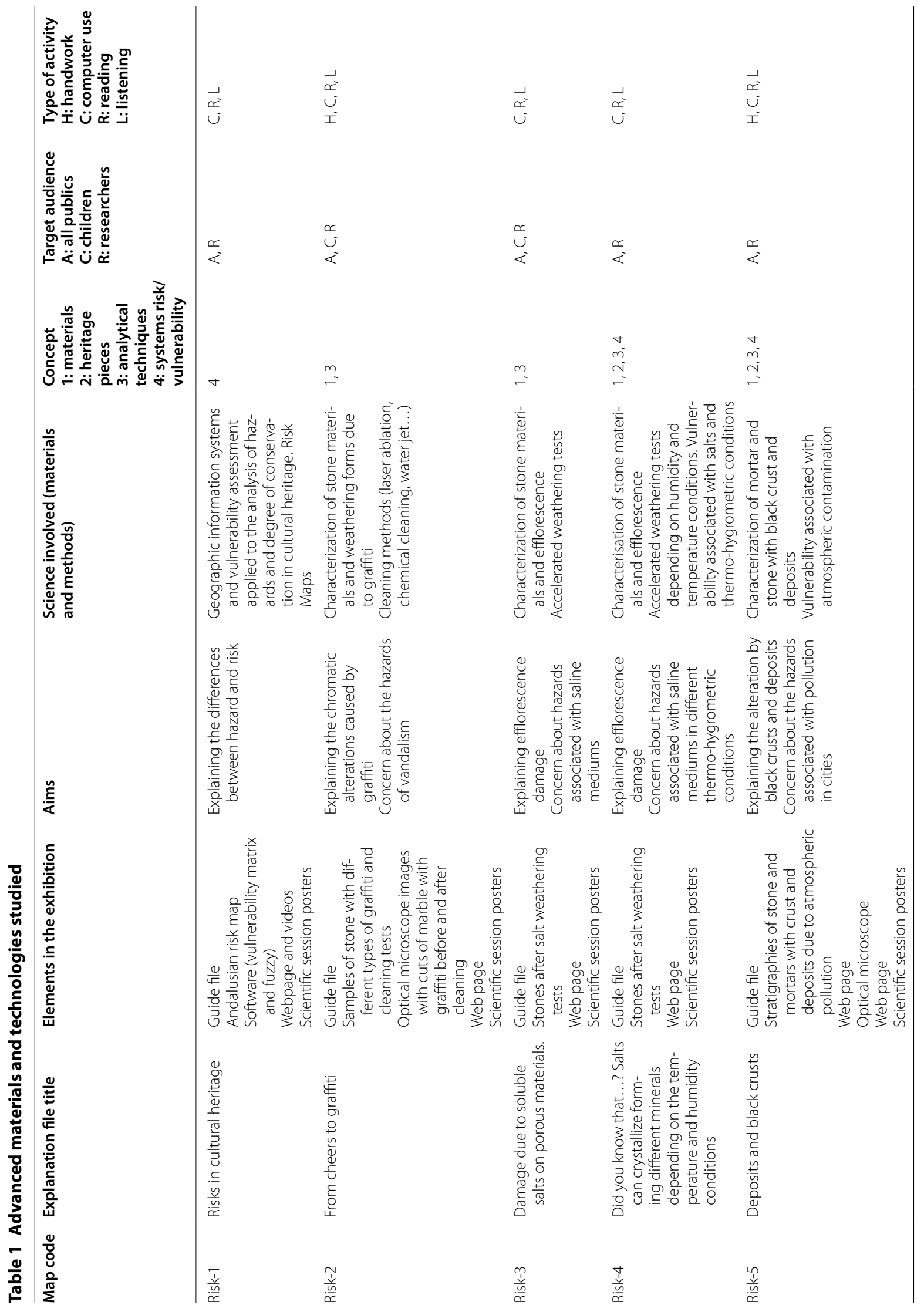




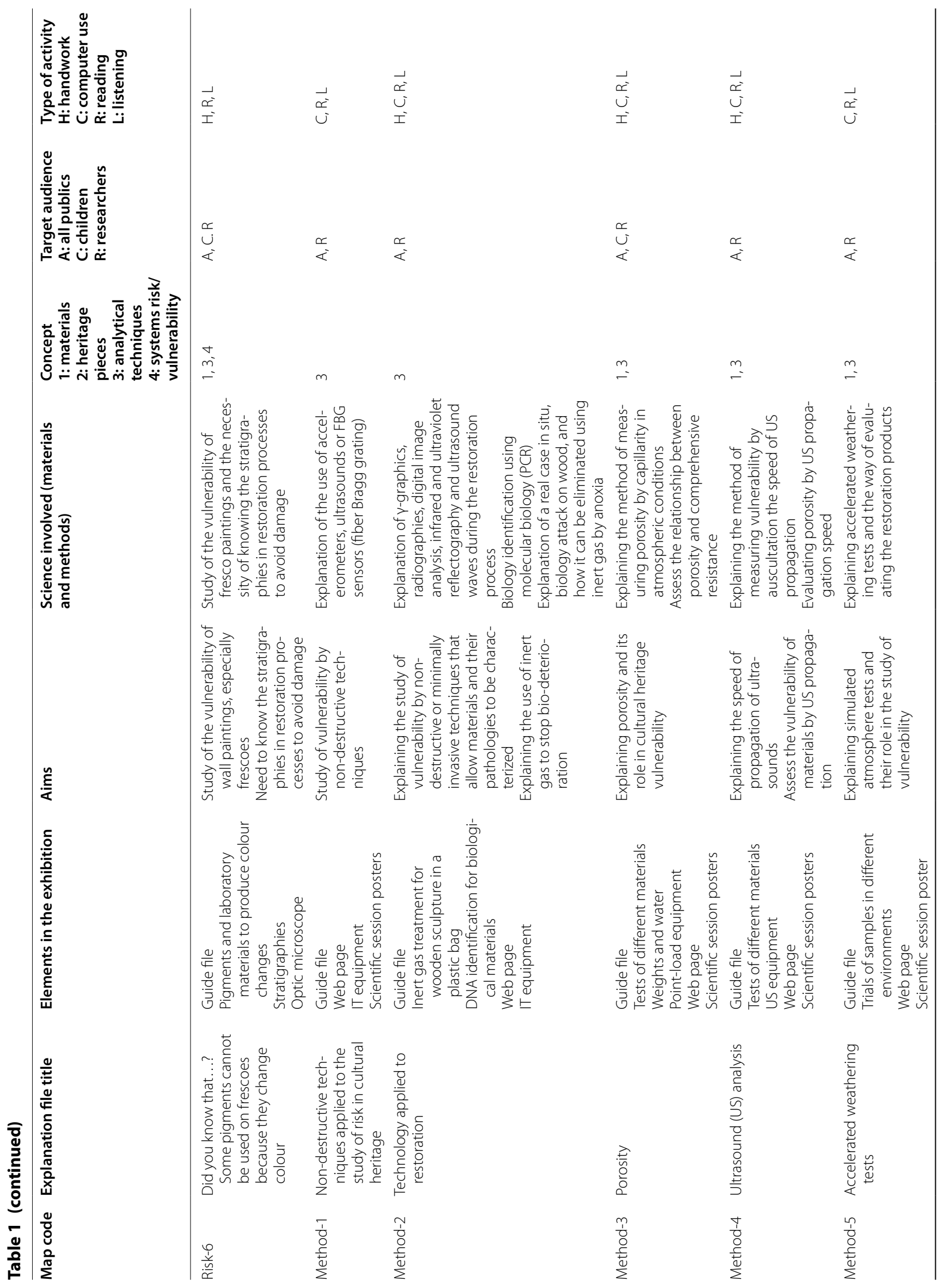




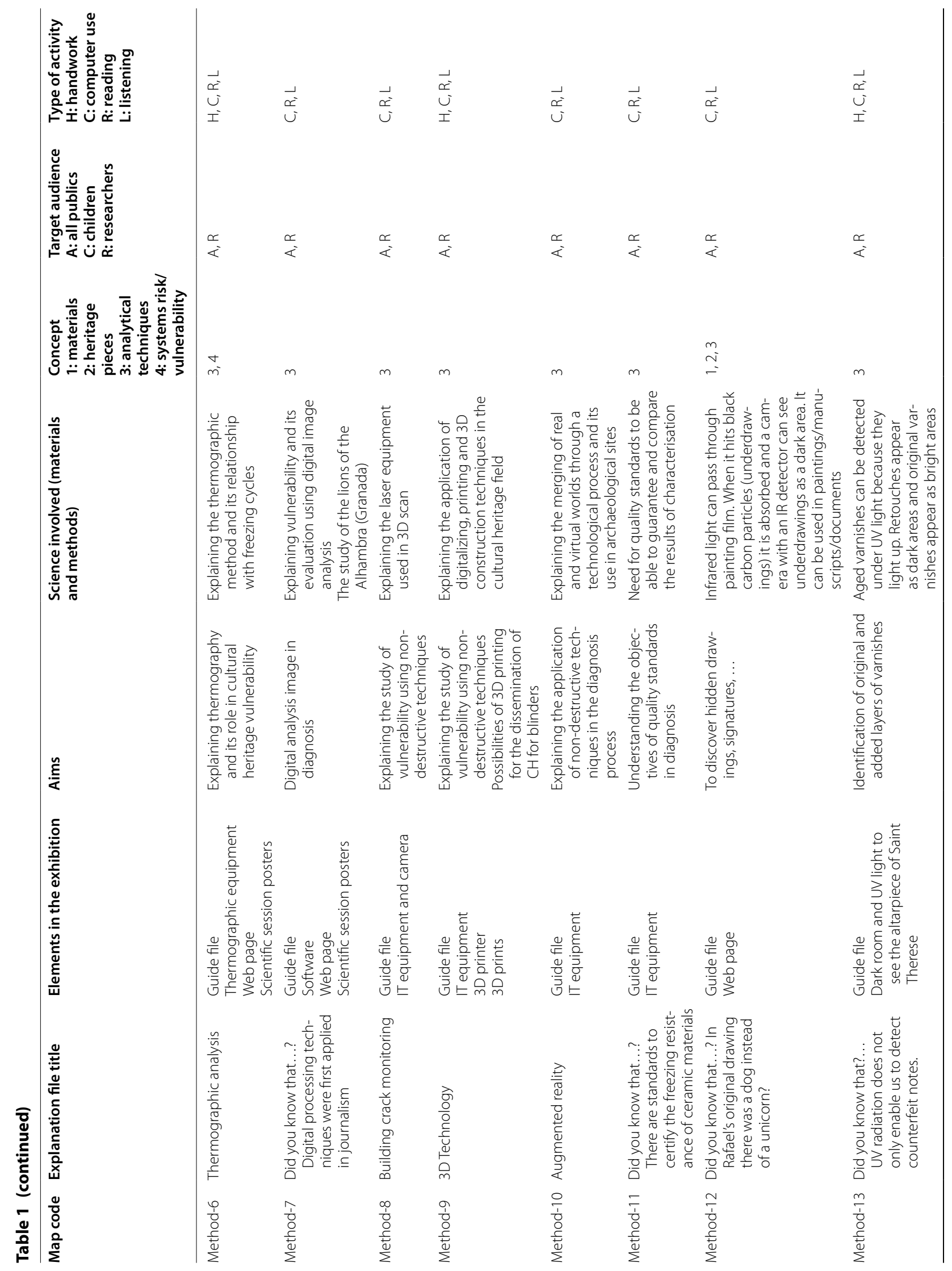




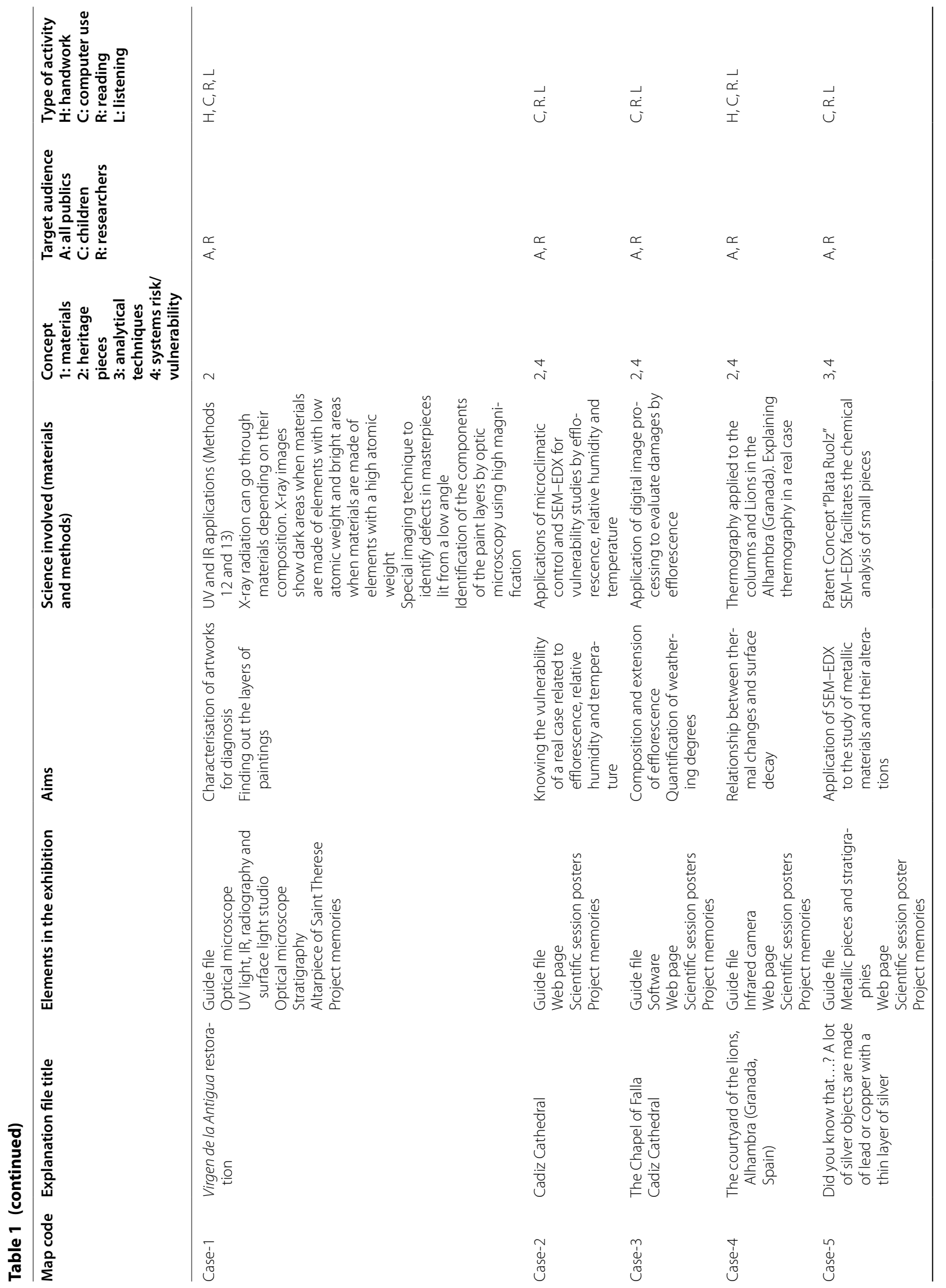




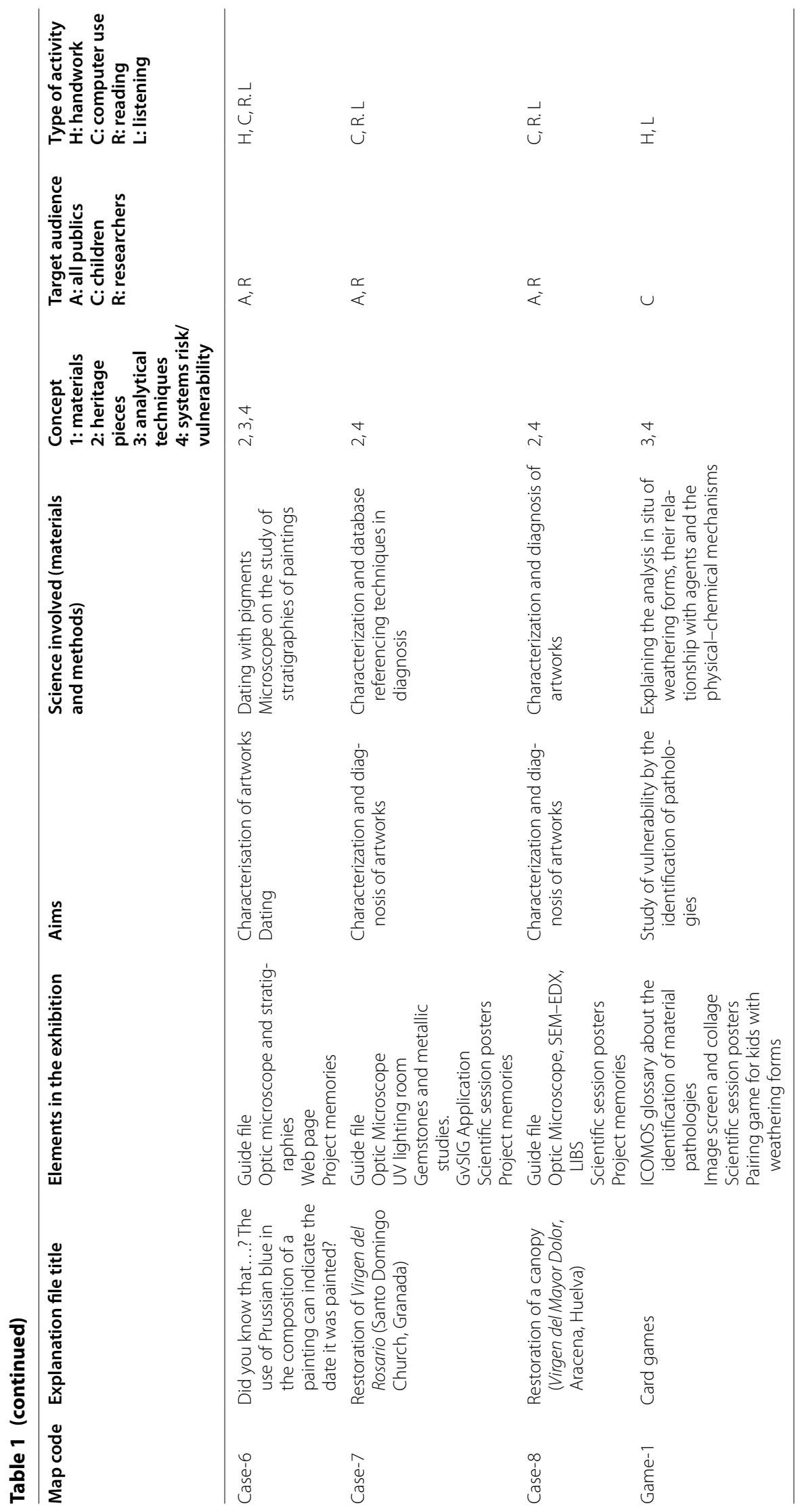


Table 2 Survey answers of visitors (number of surveys analysed 260)

\begin{tabular}{|c|c|c|c|c|c|c|}
\hline \multirow[t]{2}{*}{ Visitors Age } & $<19$ & $20-29$ & & $30-60$ & & $>60$ \\
\hline & 44.02 & 25.48 & & 29.34 & & 1.16 \\
\hline \multirow[t]{2}{*}{ Study level } & Primary & Secondary & Pre-University & & Professional training & University student \\
\hline & 5.02 & 13.13 & 6.56 & & 32.05 & 43.24 \\
\hline \multirow[t]{2}{*}{ Visitors' place of residence } & Spain & Andalusia & Granada & & Granada Province & Other countries \\
\hline & 15.06 & 28.48 & 25.48 & & 33.59 & 0.39 \\
\hline \multirow[t]{2}{*}{ Visiting the park } & For one particular exhibition & Sporadically & & Regularly & & For the first time \\
\hline & 5.81 & 31.01 & & 41.86 & & 21.32 \\
\hline \multirow[t]{2}{*}{ With whom is he/she visiting } & Friends & & Alone & & Guided & \\
\hline & 77.99 & & 9.27 & & 12.74 & \\
\hline \multirow[t]{2}{*}{ When is the visit } & Tuesday/Friday & & & Weekend & & \\
\hline & 65.64 & & & 34.36 & & \\
\hline \multirow[t]{2}{*}{ Initial interest } & INT1 & INT2 & INT3 & & INT4 & INT5 \\
\hline & 6.18 & 8.88 & 27.03 & & 25.87 & 32.05 \\
\hline \multirow[t]{2}{*}{ Previous knowledge } & CON1 & CON2 & CON3 & & CON4 & CON5 \\
\hline & 17.44 & 31.78 & 31.78 & & 10.85 & 8.14 \\
\hline \multirow[t]{2}{*}{ Evaluation of learning } & APREN5 & APREN6 & APREN7 & APREN8 & APREN9 & APREN10 \\
\hline & 0.39 & 0.39 & 5.86 & 15.63 & 31.25 & 46.48 \\
\hline \multirow[t]{2}{*}{ Quality of the space's signposting } & Excellent & Good & & Normal & & $\mathrm{Bad}$ \\
\hline & 48.45 & 39.53 & & 11.24 & & 0.78 \\
\hline \multirow[t]{2}{*}{ General space assembly } & Excellent & Good & & Normal & & $\mathrm{Bad}$ \\
\hline & 62.55 & 33.98 & & 3.47 & & - \\
\hline \multirow[t]{2}{*}{ Quality of communication } & Excellent & Good & & Normal & & Bad \\
\hline & 72.97 & 25.48 & & 1.54 & & - \\
\hline \multirow[t]{2}{*}{ Quality of texts (files) } & Excellent & Good & & Normal & & Bad \\
\hline & 44.19 & 43.41 & & 11.24 & & 1.16 \\
\hline \multirow[t]{2}{*}{ Quality of audio-visuals } & Excellent & Good & & Normal & & $\mathrm{Bad}$ \\
\hline & 41.25 & 38.91 & & 16.73 & & 3.11 \\
\hline \multirow[t]{2}{*}{ Quality of the workshop } & Excellent & Good & & Normal & & $\mathrm{Bad}$ \\
\hline & 66.41 & 30.50 & & 3.09 & & - \\
\hline \multirow{2}{*}{$\begin{array}{l}\text { Found out about the exhibition } \\
\text { through }\end{array}$} & Friends and relatives & Web & Press & & Diffusion agency & Radio \\
\hline & 47.49 & 39.00 & 6.95 & & 4.63 & 1.93 \\
\hline
\end{tabular}

Int 1, low interest, Int 5, high interest; Con 1, previous knowledge low, Con 5, previous knowledge high; Apren 1, very low evaluation of learning, Apren 10, very high evaluation of learning

Table 3 University student distribution by age group

\begin{tabular}{ll}
\hline Age & Percentage (\%) \\
\hline$<19$ & 6.4 \\
$20-29$ & 41.3 \\
$30-60$ & 52.3 \\
Total & 100 \\
\hline
\end{tabular}

aware of the park through friends in $47 \%$ of the visitors surveyed, followed by an important group that found out about it on the internet (39\%). Therefore, the conclusion is that the press did not directly affect their decision of going to the park.

The findings of this study imply that catching the interest of youth about preservation of cultural
Table 4 Distribution according to visitors' place of residence

\begin{tabular}{lc}
\hline Residence & Percentage (\%) \\
\hline Andalusia & 15.60 \\
Spain & 2.75 \\
Granada & 42.20 \\
Province & 39.45 \\
\hline
\end{tabular}

heritage is easy, perhaps due to their curiosity. Nevertheless, these results may be worthwhile for decisionmakers in science and art education to consider in order to design experiences that increase the interest surrounding $\mathrm{CH}$ preservation and meanwhile raise scientific vocations, especially among a young public. 
Table 5 Interest and average learning according to the age and study levels of the visitors

\begin{tabular}{llllll}
\hline Age & Average interest & Average learning & Level of studies & Average interest & Average learning \\
\hline$<19$ & $3.96(4)$ & $9.42(10)$ & Primary & $4.02(4)$ & $9.5(10)$ \\
$20-29$ & $3.45(3)$ & $8.97(9)$ & Secondary & $3.59(3)$ & $8.8(9)$ \\
$30-60$ & $3.51(3)$ & $9.03(9)$ & Pre-university student & $3.92(4)$ & $8.3(8)$ \\
& & & Professional training & $3.82(4)$ & $8.9(9)$ \\
& & & University student & $3.44(3)$ & $9.1(9)$ \\
Statistic indicator 3 & $\mathrm{p}=0.011$ & $\mathrm{p}=0.003$ & Statistic indicator & $\mathrm{p}=0.038$ & $\mathrm{p}=0.001$ \\
\hline
\end{tabular}

Measurement scale: $1-5$. Measuring range from 1 to 10 . Median equality test between groups

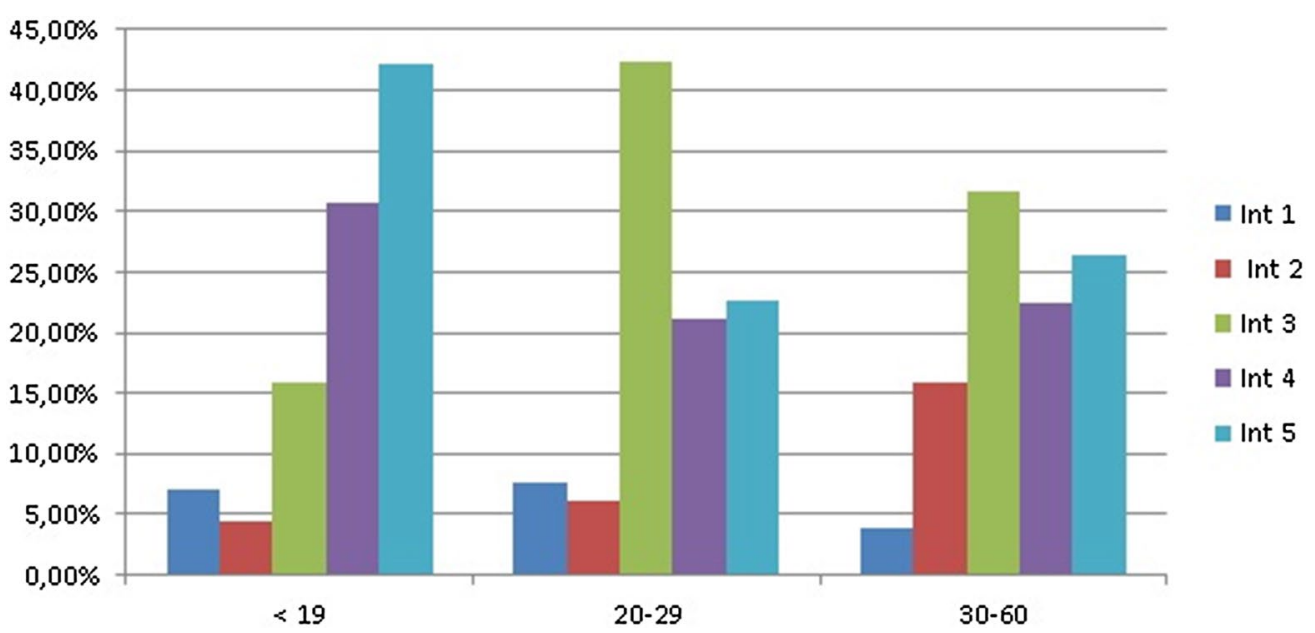

Fig. 4 Initial interest in exhibition according to age

Table 6 Diffusion of the showcase to science in the press

\begin{tabular}{llll}
\hline Medium & Range & Title of the article & Date \\
\hline Web & International & The IAPH in the informative project "Showcase to science" & $04 / 07 / 14$ \\
Facebook & International & The IAPH in the informative project "Showcase to science" & $05 / 07 / 14$ \\
Granada hoy & Regional & A showcase to heritage & $07 / 07 / 14$ \\
Ideal de Granada & Regional & How to calculate the risk of cultural heritage, in the Science Park of Granada & $07 / 07 / 14$ \\
ABC de Sevilla & Regional & Doctors of Heritage & $15 / 09 / 14$ \\
Europa press & Regional & The UPO opens a showcase to show how to calculate the risk of heritage & $07 / 07 / 14$ \\
Ahora Granada.com & Provincial & The art of calculating the risk of cultural heritage & $07 / 07 / 14$ \\
Granada Digital & Provincial & Science Park a year full of activities & $13 / 09 / 14$ \\
Granada en la Red.com & Provincial & How to calculate the risk of cultural heritage & $07 / 07 / 14$ \\
La información.com & Provincial & The UPO opens a showcase to show how to calculate the risk of heritage & $04 / 07 / 14$ \\
Teleprensa. Periódico Digital de Granada & Provincial & How to calculate the risk of cultural heritage, in the Science Park of Granada & $04 / 07 / 14$ \\
Universidad Pablo de Olavide & Provincial & How to calculate the risk of cultural heritage & \\
Ciencia y restauración & National & The hidden face of cultural heritage & \\
Facebook IAPH & International & & $07 / 07 / 14$ \\
\hline & & &
\end{tabular}




\section{Conclusions}

The Hidden Face of Cultural Heritage $(\mathrm{ScW}-\mathrm{CH})$ is a model designed for the dissemination of knowledge about risk in cultural heritage, led by researchers in collaboration with museum specialists in order to make their studies about science and cultural heritage accessible to all demographics. An innovative methodology that simulates a showcase was designed to study the four levels of hazards and vulnerability knowledge in cultural heritage, that involves a thorough understanding of materials, artworks, analytical techniques, methods, and model of risks. The exhibition spread the multidisciplinary nature of cultural heritage preservation with "the Researchers' Corner" where visitors could discover that the researchers are physicists, chemists, geologists, architects, biologists, archaeologists, historians, restorers... working together as a team. The exhibition contained materials, equipments and information sheets to help the guides to accompany visitors as storytellers. All the contents were adapted to different types of visitors, achieving their interest about this subject.

8226 visitors explored the exhibition for a period of 6 months. A survey was filled out by 260 visitors; respondents presented a medium-high initial interest in visiting this exhibition, $32 \%$ of respondents had very high interest. In contrast, respondents presented a mediumlow level of knowledge of the research, with 17\% saying they did not know anything about it. After the experience, $92 \%$ showed a very high learning level. Teenagers and children proved to be the group which had learned the most. The ratio of interest and learning in the window with the level of study shows that secondary school pupils had the highest degree of interest and learning (4.02/5, 9.5/10 average interest-learning). The evaluation of the impact highlights that the model developed is accepted by the public and valued as excellent by 6 of every 10 people surveyed. Young people showed the most interest and learned the most from this type of work, partly because of their natural curiosity. This data can be used by decision-makers in science and art education to increase scientific vocations and at the same time raise awareness about $\mathrm{CH}$ preservation in the future.

This new design, based on place-making and storytelling, is forward-thinking in achieving better awareness on cultural heritage issues and new technologies applied to the study of risk and vulnerability in cultural heritage. The project designs a holistic experience for the visitors, where science applied to art research tries to attract their emotions. Nowadays, where research dissemination to the public is a key issue in society, this approach for cultural heritage preservation needs new models and expressions similar to those shown in this paper to capture the attention of the public. Accordingly, this design may be employed for other exhibitions to improve the knowledge of society in this field of science.

\section{Abbreviations}

$\mathrm{CH}$ : cultural heritage; ICT: information and communications technologies; LIBS: laser-induced breakdown spectroscopy; LIF: laser-induced fluorescence; $\mathrm{R} \& \mathrm{D}+\mathrm{i}$ : Research \& Development \& Innovation; ScW-CH: science window titled Hidden Face of Cultural Heritage; SEM-EDX: scanning electron microscope/energy-dispersive $x$-ray; SPSS: Statistical Package for the Social Sciences.

\section{Authors' contributions}

PO: Head of RIVUPH Project, has participated in the instructive design of the exhibition in both phases, especially in the dissemination of advanced materials and technologies of Table 1 (Risk 1-5; Method 1, 3-6, 8-10; Case 2, 4, 5, 7, 8 and Game 1). She was a major contributor in writing the manuscript and the analysis and evaluation of results. She participated in storyteller formation and inauguration. She has written guide files in a language accessible to different levels. RO: researcher of RIVUPH Project, has participated in the instructive design of the exhibition in both phases and especially in the dissemination of advanced materials and technologies of Table 1 (Risk 1-5, Method 1, 3-5, 7-9; Case 5, 7, 8 and Game 1). She was a major contributor in writing the manuscript and the analysis and evaluation of results. She participated in storyteller formation and inauguration. She has written guide files in a language accessible to different levels. JMM: researcher of RIVUPH Project, has participate in the instructive design of the exhibition in both phases and especially in the dissemination of advanced materials and technologies of Table 1 (Risk 1-5; Method 1, 3-5; Case 7, 8 and Game 1). He participated in storyteller formation and inauguration. He has written guide files in a language accessible to different levels. RRG: statistic, researcher of UPO. She was in charge of the social analysis of the surveys. MAV: researcher of RIVUPH Project, has participate in the instructive design of the exhibition in both phases and especially in the dissemination of advanced materials and technologies of Table 1 (Risk 1, 3-5; Method 1, 3, 4, 6, 7 and Case 2-4). She participated in storyteller formation and inauguration. She has written guide files in a language accessible to different levels. MAGM: researcher of RIVUPH Project, has participated in the instructive design of the exhibition in the first phase and especially in the dissemination of advanced materials and technologies of Table 1 (Risk 1, 2, 6; Method 11-13 and Case 1, 5-8). She participated in storyteller formation and inauguration. She has written guide files in a language accessible to different levels. MS: researcher of IAPH, has participated in the instructive design of the exhibition in the first phase and especially in the dissemination of advanced materials and technologies of Table 1 (Method 2). She participated in storyteller formation and inauguration. She has written guide files in a language accessible to different levels. LL: specialist in dissemination of IAPH has participate in the instructive design of the exhibition in the first phases and oversaw the state of art. She participated in the inauguration. She has overseen guide files in a language accessible to different levels. CG: member of museum Science Park of Granada and leader of the meetings to evaluate the space and the examples to be shown, she has participated in the instructive design of the exhibition in both phases and in the design of the space, formation of storyteller, head of development of the dissemination materials, she was in charge to collect the surveys, assembly of the exhibition with the training of guides, inauguration and exposition. JMGB: researcher of RIVUPH Project, has participate in the instructive design of the exhibition in both phases and especially in the dissemination of advanced materials and technologies of Table 1 (Risk 1). He participates in storyteller formation and the inauguration. JB: researcher of UPO, has participate in the instructive design of the exhibition in both phases and especially in the dissemination of advanced materials and technologies of Table 1 (Risk 1, 3, 4 and Method 3). All authors read and approved the final manuscript.

\footnotetext{
Author details

${ }^{1}$ Dept. de Sistemas Físicos, Químicos y Naturales, Universidad Pablo de Olavide, Carretera de Utrera km 1, 41013 Seville, Spain. ${ }^{2}$ Dept. de Economía, Métodos cuantitativos e Ha económica, Universidad Pablo de Olavide, Carretera de Utrera km 1, 41013 Seville, Spain. ${ }^{3}$ Dept. Cristalografía, Mineralogía y Química Agrícola, Universidad de Sevilla, C/Profesor García González, no 1, Seville, Spain. ${ }^{4}$ Instituto Andaluz del Patrimonio Histórico, Avenida de los Descubrimientos S/N, 41092 Seville, Spain. ${ }^{5}$ Principia Science Centre Málaga,
} 
Avenida de Luis Buñuel, n6, 29011 Málaga, Spain. ${ }^{6}$ Dept. Construcciones Arquitectónicas II, Universidad de Sevilla, Avda Reina Mercedes, no 1, Seville, Spain.

\section{Acknowledgements}

The authors gratefully acknowledge the collaboration between UPO\&IAPH, the Project RIVUPH and the Science Window.

\section{Competing interests}

The authors declare that they have no competing interests.

\section{Availability of data and materials}

The datasets used and/or analysed during the current study are available from the corresponding author on reasonable request.

\section{Consent for publication}

All authors of the manuscript have consented for publication.

\section{Ethics approval and consent to participate}

All authors of the manuscript have read and agreed to ethics approval and have consented to participate.

\section{Funding}

This study has been partially supported by the agreements UPO\&IAPH and Junta de Andalucía Projects RIVUPH (HUM-6775) and Science Window.

\section{Publisher's Note}

Springer Nature remains neutral with regard to jurisdictional claims in published maps and institutional affiliations.

Received: 19 April 2018 Accepted: 28 September 2018

Published online: 10 October 2018

\section{References}

1. Bornmann L, Mutz R. Growth rates of modern science: a bibliometric analysis based on the number of publications and cited references. J Assoc Inf Sci Technol. 2015;66:2215-22.

2. Watters JJ, Christensen C. Vocational education in science technology, engineering and maths (stem): curriculum innovation through industry school partnerships. In: E-Book proceedings of the Esera 2013 conference: science education research for Evidence-based Teaching and Coherence Learning. European Science Education Research Association, Nicosia, Cyprus. 2013. pp. 89-110.

3. Burns TW, O'Connor DJ, Stocklmayer SM. Science communication: a contemporary definition. Public Underst Sci. 2003;12:183-202.

4. Lesen AE, Rogan A, Blum MJ. Science communication through art: objectives, challenges, and outcomes. Trends Ecol Evol. 2016;31:657-60.
5. Lobovikov-Katz A, Moropoulou A, Konstanti A, Calderón PO, Van Grieken R, Worth S, Cassar J, De Angelis R, Biscontin G, Izzo FC. Tangible versus intangible in e-learning on cultural heritage: from online learning to onsite study of historic sites. In: Lect. Notes Comput. Sci. (including Subser. Lect. Notes Artif. Intell. Lect. Notes Bioinformatics). Springer, Cham. 2014. Pp. 819-28

6. Soto-Martín O. Heritage conservation in secondary education curriculum a didactic proposal based on the application of ICT. Procedia Soc Behav Sci. 2012;51:782-6.

7. Obra Social "La Caixa", FECYT E. ¿Cómo podemos estimular una mente científica? Estudio Sobre Vocaciones Científicas. 2015.

8. Roigé X. Science museums and cultural images of modernity: scientific communication, new identities and sociopolitical constraints on science museums in Spain. In: Schiele B, Claessens M, Shi S, editors. Science communication in the world. Practices, Theories and Trends. Dordrecht: Springer; 2012. p. 211-24.

9. Oliveros Ruiz MA, Vargas Osuna L, Valdez Salas B, Schorr Wienner M, Sevilla Garcia J, Cabrera Cordova E, Nedev R, Ibarra R. The importance of teaching science and technology in early education levels in an emerging economy. Bull Sci Technol Soc. 2014;34:87-93.

10. Meyer É, Grussenmeyer P, Perrin J-P, Durand A, Drap P. A web information system for the management and the dissemination of cultural heritage data. J Cult Herit. 2007:8:396-411.

11. Axhamn J, Guibault L. Cross-border extended collective licensing: a solution to online dissemination of Europe's cultural heritage? Final report prepared for Europeana Connect. 2011.

12. Forbes CT. This is inquiry right ? Strategies for effectively adapting elementary science lessons Strategies for effectively adapting elementary. 2012.

13. Macdonald S. Interconnecting: museum visiting and exhibition design. CoDesign. 2007:3:149-62.

14. Ciolfi L, Bannon LJ, Fernstrom M, Fernström M. Including visitor contributions in cultural heritage installations: designing for participation. Mus Manag Curatorship. 2008;23:353-65.

15. Ahmad S, Abbas MY, Yusof WZM, Taib MZM. Museum learning: using research as best practice in creating future museum exhibition. Procedia Soc Behav Sci. 2013;105:370-82.

16. Hashim AF, Taib MZM, Alias A. The integration of interactive display method and heritage exhibition at museum. Procedia Soc Behav Sci. 2014;153:308-16.

17. Palombini A. Storytelling and telling history. Towards a grammar of narratives for cultural heritage dissemination in the Digital Era. J Cult Herit. 2017;24:134-9.

18. Alanazi MS. The impact of storytelling to enhance thinking skills of primary school students: a contextual study of Saudi Arabia. Int J Educ Res Innov. 2018;10:1-26.

\section{Submit your manuscript to a SpringerOpen ${ }^{\circ}$ journal and benefit from:}

- Convenient online submission

- Rigorous peer review

- Open access: articles freely available online

- High visibility within the field

- Retaining the copyright to your article

Submit your next manuscript at $\boldsymbol{\nabla}$ springeropen.com 